\title{
Novel advances in cardiac rehabilitation
}

\section{Position paper from the Working Group on Preventive Cardiology and Cardiac Rehabilitation of the Netherlands Society of Cardiology}

\author{
T. Vromen · R. W. M. Brouwers · H. T. Jorstad · R. A. Kraaijenhagen · R. F. Spee · M. E. Wittekoek · M. J. Cramer · \\ J. M. C. van Hal · L. Hofstra - P. M. J. C. Kuijpers · E. C. de Melker · S. F. Rodrigo - M. Sunamura · \\ N. H. M. K. Uszko-Lencer · H. M. Kemps
}

Accepted: 3 May 2021 / Published online: 10 June 2021

(C) The Author(s) 2021

\begin{abstract}
Cardiac rehabilitation (CR) has evolved as an important part of the treatment of patients with cardiovascular disease. However, to date, its full potential is fairly underutilised. This review discusses new developments in CR aimed at improving participation rates and long-term effectiveness in the general cardiac population. It consecutively highlights new or challenging target groups, new delivery modes and new care pathways for CR programmes. These new or challenging target groups include patients with atrial fibrillation, obesity and cardiovascular disease, chronic coronary syndromes, (advanced) chronic heart failure with or without intracardiac devices, women and frail elderly patients. Also, the current evidence regarding cardiac telerehabilitation and loyalty programmes is discussed as new delivery modes for CR. Finally, this paper discusses novel care
\end{abstract}

\section{T. Vromen ( $\square)$ \\ Department of Cardiology, Maastricht University Medical Centre, Maastricht, The Netherlands \\ tom.vromen@mumc.nl}

R. W. M. Brouwers · R. F. Spee · H. M. Kemps

Department of Cardiology, Máxima Medical Centre, Veldhoven, The Netherlands

\section{H. T. Jorstad}

Department of Cardiology, Amsterdam University Medical Centre, University of Amsterdam, Amsterdam, The Netherlands

\section{R. A. Kraaijenhagen}

CardioVitaal Cardiac Rehabilitation, Amsterdam, The Netherlands

M. E. Wittekoek

HeartLife Klinieken, Utrecht, The Netherlands

\section{J. Cramer}

Department of Cardiology, University Medical Centre Utrecht, Utrecht, The Netherlands pathways with the integration of $\mathrm{CR}$ in residual risk management and transmural care pathways. These new developments can help to make optimal use of the benefits of CR. Therefore we should seize the opportunities to reshape current CR programmes, broaden their applicability and incorporate them into or combine them with other cardiovascular care programmes/pathways.

Keywords Cardiac rehabilitation - Telerehabilitation • Secondary prevention - Transmural care

\section{Background and aims}

Over the past few decades, cardiac rehabilitation (CR) has become an important part of the management

J. M. C. van Hal
Department of Cardiology, Slingeland Hospital,
Doetinchem, The Netherlands

L. Hofstra

Cardiology Centres Netherlands, Utrecht, The Netherlands

P. M. J. C. Kuijpers · N. H. M. K. Uszko-Lencer

Department of Cardiology, Maastricht University Medical Centre, Maastricht, The Netherlands

\section{E. C. de Melker}

Department of Cardiology, Onze Lieve Vrouwe Gasthuis, Amsterdam, The Netherlands

\section{S. F. Rodrigo}

Basalt Rehabilitation, Leiden, The Netherlands

M. Sunamura

Capri Cardiac Rehabilitation, Rotterdam, The Netherlands

H. M. Kemps

Department of Industrial Design, Eindhoven University of Technology, Eindhoven, The Netherlands 
of patients with cardiovascular diseases (CVD). Given improvements in the treatment of acute CVD, the role of CR in the modern era has changed from interventions targeted at physical recovery in the 1990s to comprehensive interventions also focussing on psychosocial aspects, lifestyle, risk factors and work resumption. Accordingly, the RAMIT trial, evaluating a low-dose CR programme, mainly focussing on shortterm improvement of exercise capacity, failed to show positive effects in the modern era [1], whereas large, real-life cohort studies evaluating comprehensive multimodal programmes have demonstrated that CR is associated with a substantial survival benefit [2-4]. Furthermore, recent meta-analyses showed that multimodal CR is associated with a reduction in cardiovascular mortality and hospitalisation $[5,6]$. Therefore, CR is strongly recommended in current guidelines for patients with coronary artery disease (CAD) [7]. In addition, the body of evidence for the effectiveness of CR in other patient groups is growing [8, 9].

Despite the proven effectiveness of CR, implementation remains unsatisfactory and low participation rates are a major problem. Both in the Netherlands [10] and other European countries [11], over 50\% of eligible patients do not receive CR. In addition to financial barriers for upscaling CR capacity, organisational and patient-related factors can also influence participation. An important reason for non-participation is that conventional CR programmes typically are group-based and, as such, not well tailored to individual needs and preferences [12]. Logistic issues such as transportation and working obligations also form important barriers, resulting in lower participation rates [13]. A central challenge in both secondary prevention of CVD and CR in particular is the poor long-term adherence to a healthy lifestyle and the presence of considerable residual cardiovascular risk. Data from the EUROASPIRE-IV study show that risk factor control and lifestyle behaviours in CVD patients are still far from optimal [14]. Therefore, there is a need for new strategies in CR. These include, for example, more personalised CR delivery modes, preferably in the patients' home environment. To improve (long-term) adherence, programmes should be made more appealing for a broad population and, ideally, patients should continuously be stimulated to maintain lifestyle changes, even after finishing CR. The aim of the current paper is (a) to outline the broadened scope of CR, highlighting novel and challenging target groups and (b) to discuss new developments in $\mathrm{CR}$ aimed at improving participation rates and longterm effectiveness in the general cardiac population by highlighting novel delivery modes and care pathways.

\section{Methods}

This article presents a position statement from the Working Group on Preventive Cardiology and Cardiac
Rehabilitation of the Netherlands Society of Cardiology. A core author group (R.B., H.J., R.S., R.K., H.K. and T.V.) was composed of members of this working group, highly experienced in the field of CR. The other members of the working group were involved as reviewers of the drafted manuscript. The core author group organised digital brainstorming sessions to determine (a) which target groups should be highlighted in this paper and (b) which new developments in Dutch CR practice should be discussed in the novel delivery modes and novel care pathways sections. This selection was based on expert opinion and a consensus meeting within the core author group and presented to the document reviewers. A group of patients was identified as 'novel' when there was no absolute indication for CR in the current Dutch guideline [15] but for which recent research has shown beneficial effects of CR programmes. Patient groups were identified as 'challenging' when recent research indicated low participation rates, or when specific tailoring of exercise programmes is required.

\section{Novel and challenging target groups}

\section{Novel target groups}

There is a growing amount of evidence showing beneficial effects of CR in groups that are not registered as having an absolute indication for $\mathrm{CR}$ in the latest Dutch guidelines [15]. These novel target groups include, but are not limited to, patients with atrial fibrillation (AF), chronic heart failure $(\mathrm{CHF})$ and devices and different manifestations of the chronic coronary syndrome (CCS).

\section{Atrial fibrillation}

Recent trials clearly showed that risk factor modification and healthy lifestyles, in particular weight loss and exercise, are important in the management of $\mathrm{AF}$ patients ([16, 17]; Tab. 1). However, as mostly demonstrated by smaller trials with quality of evidence ranging from moderate to very low, CR for patients with AF seems to improve symptom burden, quality of life and exercise capacity $([9,18]$; Tab. 1$)$. While awaiting larger trials with better methodology and longer follow-up, CR should at least be considered in all motivated patients with AF, especially in patients with obesity that wish to improve lifestyle-related risk factors [19].

\section{Chronic heart failure and devices}

$\mathrm{CHF}$ is a relative indication for CR in the latest Dutch guideline, but in a newer European guideline it has a class la recommendation $[15,20]$. However, CR uptake in this group appears very low [10]. Therefore, more patients with CHF should be offered a CR programme, personalised to patient characteristics in this very heterogeneous group. Within this group, patients with advanced heart failure and a ventricular assist device (VAD) are a new and emerging group attending 


\begin{tabular}{|c|c|c|c|c|}
\hline Study group & Therapy & Endpoints & Results & Reference \\
\hline $\mathrm{AF}$ & RCT lifestyle therapy and RFM vs usual care & $\begin{array}{l}\text { Arrythmia-free survival } \\
\mathrm{FU} \approx 6 \text { years }\end{array}$ & HR 0.38 (95\% Cl 0.25-0.59) & Pathak et al. [16] \\
\hline AF & $\begin{array}{l}\text { Interventional study on dietary advice and } \\
\text { exercise (no control group) }\end{array}$ & $\begin{array}{l}\text { AF recurrence } \\
\text { FU } \approx 4 \text { years }\end{array}$ & $\begin{array}{l}>10 \% \text { vs } 3-9 \% \text { HR } 0.56(0.4-0.77) \\
3-9 \% \text { vs }<3 \% \text { HR } 0.48(0.33-0.63)\end{array}$ & Pathak et al. [17] \\
\hline AF & Systematic review and meta-analysis & Exercise capacity & $1.6(0.11-3.08) \uparrow V_{2, \text { peak }}(\mathrm{ml} / \mathrm{kg}$ per minute) & Smart et al. [9] \\
\hline CR indication & Cohort study & CR uptake & $\begin{array}{l}\text { Age }>709.0 \% \\
\text { Age }>803.3 \% \\
\text { CHF } 3.7 \%\end{array}$ & $\begin{array}{l}\text { Van Engen-Verheul } \\
\text { et al. [10] }\end{array}$ \\
\hline VAD & Systematic review ECR & $\begin{array}{l}\text { Exercise capacity } \\
\text { Adverse events }\end{array}$ & $\begin{array}{l}-2.2+V_{2, \text { peak }}(\mathrm{ml} / \mathrm{kg} \text { per minute) } \\
-n=2 \text { in } 121 \text { patients ( } 1 \mathrm{NSVT}, 1 \text { syncope) }\end{array}$ & Alswyan et al. [8] \\
\hline ICD & Systematic review ECR & $\begin{array}{l}\text { Exercise capacity } \\
\text { Shocks during exercise }\end{array}$ & $\begin{array}{l}-2.6 \text { (range: } 2.2-3.2) \uparrow W_{2, \text { peak }}(\mathrm{ml} / \mathrm{kg} \text { per } \\
\text { minute) } \\
-2.2 \%\end{array}$ & Alswyan et al. [8] \\
\hline CRT & Systematic review ECR & Exercise capacity & $-3.2 \uparrow \mathrm{V}_{2, \text { peak }}(\mathrm{ml} / \mathrm{kg}$ per minute) & Alswyan et al. [8] \\
\hline SAP & RCT exercise programme vs $\mathrm{PCl}$ & $\begin{array}{l}\text { Event-free survival } \\
\text { FU } 1 \text { year }\end{array}$ & $88 \%$ vs $70 \% p<0.001$ & $\begin{array}{l}\text { Hambrecht et al. } \\
\text { [23] }\end{array}$ \\
\hline NOCAD & Interventional study CR (no control group) & Exercise capacity & Increase from 6.5 to 8.1 METS $p<0.001$ & Szot et al. [26] \\
\hline NOCAD & Meta-analysis CR & Exercise capacity & $\begin{array}{l}-31-36 \% \uparrow W_{\text {peak }}(\mathrm{W}) \\
-15-26 \% \uparrow \mathrm{V}_{2, \text { peak }}(\mathrm{l} / \mathrm{min})\end{array}$ & $\begin{array}{l}\text { Kissel and Nikoletou } \\
\text { [27] }\end{array}$ \\
\hline $\begin{array}{l}\text { Elderly CAD } \\
\text { patients }\end{array}$ & Cohort study CR vs no CR & Mortality 5 years & $34 \%$ RRR & Suaya et al. [29] \\
\hline CAD & Cohort study & CR uptake & $\begin{array}{l}\text { Women } 15.5 \% \\
\text { Men } 25.4 \%\end{array}$ & Colbert et al. [32] \\
\hline $\begin{array}{l}\text { CAD and } \\
\text { obesity }\end{array}$ & $\begin{array}{l}\text { RCT high-caloric vs standard exercise pro- } \\
\text { gramme }\end{array}$ & Weight loss (kg) & $8.2(\mathrm{SD} \pm 4)$ vs $3.7( \pm 5) p<0.001$ & Ades et al. [36] \\
\hline CAD and LRF & $\begin{array}{l}\text { RCT lifestyle programme add-on to CR vs } \\
\text { standard CR }\end{array}$ & Weight loss $>5 \%$ & $27 \%$ vs $14 \% p<0.001$ & Minneboo et al. [37] \\
\hline
\end{tabular}

CR. The limited number of trials for CR in this group demonstrate its safety and beneficial effects on exercise capacity ([8]; Tab. 1). In the Netherlands, only a few specialised rehabilitation centres have experience with CR in this patient group. Therefore, we recommend that CR for patients with a VAD should take place in experienced CR centres.

Current guidelines provide limited information on the effectiveness of CR in patients with an implantable cardioverter defibrillator (ICD) or cardiac resynchronisation therapy, while the number of patients with such devices is increasing [21]. A systematic review shows that exercise-based CR in patients with devices is safe and effective for improving exercise capacity and managing anxiety in ICD patients ([8]; Tab. 1). However, the optimal characteristics of exercise training in these patients remain to be determined. While awaiting more specific recommendations, as a rule of thumb, the maximal heart rate during exercise should be limited to 20 beats/min under the detection limit of the ICD [21].

\section{Chronic coronary syndromes}

The 2019 European Society of Cardiology (ESC) guidelines for CCS have drastically changed the management of CAD [7]. While earlier guidelines focused on stable or unstable disease, the new guidelines acknowledge the vast scope of clinical presentations that comprise CAD. Regardless of the actual stage of the CCS, the ESC endorses CR as a class 1A recommendation in all patients to achieve a healthy lifestyle and manage risk factors. However, CR in some CCS subgroups needs attention.

As such, there is an urgent need for well-conducted randomised trials of CR in patients with newly diagnosed stable angina pectoris (SAP)—with referral of patients to CR before an invasive strategy is pursued. A large recent trial demonstrated that an invasive approach is not superior to a conservative strategy in preventing major cardiovascular events or mortality in SAP patients. In this trial patients received basic lifestyle advice but did not follow a comprehensive CR programme [22]. Smaller trials showed impressive results using CR in SAP, even suggesting superiority compared with percutaneous coronary interventions ([23]; Tab. 1). The mechanism for this effect seems to be the stimulation of collateral growth ensuring better coronary perfusion [24]. Interestingly, in patients with intermittent claudication due to peripheral artery disease, exercise training and lifestyle therapy have already largely replaced vascular interventions as the treatment of first choice [25]. Whether CR is also su- 
perior to an invasive approach in patients with SAP needs to be investigated in larger trials.

Furthermore, approximately $70 \%$ of women and $30 \%$ of men undergoing a coronary angiogram for angina symptoms are found to have non-obstructive CAD (NOCAD). This large, heterogeneous group of patients comprises distinct vasomotor disorders such as vasospastic angina and microvascular disease, caused by endothelial dysfunction [27]. Adequate lifestyle measures promote well-being, reduce symptoms and improve cardiovascular function and exercise tolerance in patients with $\operatorname{NOCAD}([26,27]$; Tab. 1). Therefore, CR should at least be considered for NOCAD patients in the future.

\section{Challenging target groups}

Two subgroups of patients (i.e. elderly patients and women) were identified as challenging because of low participation rates [10]. Patients with obesity and CVD were classified as challenging because of the need for specific tailoring of rehabilitation programmes.

\section{Frail and elderly patients}

Elderly patients are highly underrepresented in CR [10] and older age seems to be a predictive factor for not following a CR programme ([28]; Tab. 1). However, patients aged above 65 years derive a large mortality benefit from attending CR [29] and show sustainable results in improved exercise capacity [30]. In 2016 the European Association of Preventive Cardiology published a call for action to include frail and elderly patients in CR programmes, as frailty can to a large degree be positively influenced by personalised CR programmes [31]. In the future, more frail and elderly patients should be offered participation in CR programmes.

\section{Women}

Women and men benefit equally from CR, but women attend CR less frequently than men both in the Netherlands and other European countries ([10, 32]; Tab. 1). In contrast, women mostly have worse cardiovascular risk factor profiles and lower exercise capacity [33]. Also, anxiety and depression are more likely to be present in women. These gender specificities need to be taken into account to tailor CR programmes in order to increase their uptake and positive effects in women [34].

\section{Obesity}

The majority of patients currently entering CR are overweight $(80 \%)$ [35], and the rates of overweight and obesity, with associated negative health consequences, continue to rise globally. Also, 6 months after a cardiac incident, even after following in a CR programme, half of the patients are still overweight [14]. However, there is a steadily increasing body of evidence for successful weight loss in the setting of
CR when a tailored programme is prescribed. This is demonstrated by successful initiatives such as dedicated CR weight-loss programmes showing more weight loss with high-caloric exercise programmes [36] or nurse-coordinated referral to commercial lifestyle programmes as a CR add-on ([37]; Tab. 1). The OPTICARE XL RCT (NTR6181) will give clinicians important information on the effects of a current CR programme in obese individuals.

\section{Novel delivery modes}

\section{Cardiac telerehabilitation}

Several alternative modes of CR delivery have been developed in an attempt to increase CR utilisation and optimise its long-term effects [38]. As such, cardiac telerehabilitation (CTR) has drawn attention in recent years. In CTR, parts of the CR programme are executed in a patient's home environment, using remote communication (e.g. web or mobile applications) and wearable devices (e.g. heart rate monitors, accelerometers). Several meta-analyses and systematic reviews have shown that multidisciplinary or exercise-based CTR is safe and at least as (cost-)effective as traditional centre-based CR [39, 40]. The ESC therefore considers CTR to be a valid alternative to conventional CR [41] and, consequently, CTR is endorsed in the Dutch multidisciplinary CR guideline [42]. According to this guideline, remotely supervised exercise training may be recommended in low- to moderate-risk patients with CAD and remotely supervised psycho-educational prevention therapy may be recommended in low- to high-risk patients, regardless of the underlying cardiac diagnosis.

Future developments may increase the (longterm) effectiveness of CTR, for instance by applying e-persuasion (e.g. gamification) and personalisation strategies, or by prolonging CTR towards a long-term lifestyle management intervention, incorporating relapse prevention and rewards to support sustainable healthy lifestyle behaviour.

\section{Loyalty programmes}

Following the notion that people act in a reasoned fashion, many rehabilitation and lifestyle modification programmes focus on enhancing an individual's health literacy, efficacy beliefs and the motivation to adopt a healthy lifestyle. This does not suffice, however, as strong drivers of health behaviours are often non-reasoned [43]. To achieve sustained healthy living, it is crucial that interventions empower patients to cope with both reasoned and non-reasoned processes and, if interventions address both, the individual and environmental factors that drive behaviour [43]. Furthermore, to ensure long-term uptake of behavioural interventions, they are preferably embedded in day-to-day routines and a patient's home 
environment. In addition, meta-analyses show that rewarding health increases the adoption of a healthy lifestyle [44].

A public-private partnership, the BENEFIT consortium, uniting (academic) hospitals, rehabilitation centres, general practices, lifestyle entrepreneurs and patient federations, is currently creating an ecosystem integrating the necessary ingredients for sustained healthy living [45]. The BENEFIT approach connects initiatives from various private and public parties, such as online or offline coaching, lifestyle modification applications and self-monitoring devices. Healthy living is made more attractive with challenges and rewards for attending appointments with healthcare providers, adhering to evidence-based lifestyle-change programmes and coaching and selfmonitoring lifestyle behaviours. These rewards can be exchanged for discounts on health-related goods and services. Patients are provided with a personal health application which can store their health-related information, connect with wearables, supports teleconsultation and provides access to digital lifestyle interventions. Within their digital environment, patients can share data with health professionals in the different care settings, enabling coaching and monitoring of patients 'at a distance' and ensuring the continuity of care and transmural access to lifestyle interventions. The BENEFIT approach is currently being evaluated in a stepped-wedge roll-out.

\section{Novel care pathways}

Currently, CR and traditional cardiovascular risk management are often suboptimally integrated. Whereas CR is usually targeted at physical training, psychosocial recovery and lifestyle management only, medical treatment of traditional risk factors such as hypertension, dyslipidaemia and diabetes is performed separately. Yet, it has been shown that an integrated approach including both lifestyle therapy and medical treatment can be particularly effective [25, 46]. Also, poor alignment of CR programmes with primary care secondary prevention programmes hampers the optimal long-term effectiveness of CR. Typically, a CR programme lasts for 3 months and patients are included in primary care cardiovascular risk management programmes substantially later, often 1 year after a cardiovascular incident. This results in a treatment gap, frequently leading to discontinuing personalised long-term prevention goals set out during the CR programme and consequently to a relapse into unhealthy behaviours [14].

\section{Integration of CR in residual risk management}

Residual risk, i.e. 'the risk of new vascular events or progression of established vascular damage' is an important emerging challenge in CR and secondary prevention of CVD [47]. While healthy lifestyle changes form the cornerstone of any strategy to reduce residual risk, numerous new and upcoming pharmacological treatment options are increasingly becoming available for patients with CVD. These include intensive low-density-lipoprotein-lowering strategies, new antithrombotic and anticoagulation strategies and new antidiabetic treatment options [7]. Pending data from ongoing or recently published trials, novel pharmacological residual risk treatment targets are also becoming available, such as triglyceride level, inflammation, lipoprotein A level and even obesity [48, 49]. However, there is an unmet need for a consensus as well as for decision-making tools to help clinicians identify which patients should receive which pharmacological treatment, in which sequence, to what degree or level of intensity. Patient perspectives and preferences are urgently needed when designing clinical programmes to address residual risk. Furthermore, a number of the new pharmacological strategies carry considerable costs, and cost-effectiveness should be taken into account, especially against the background of comparable effects through lifestyle changes which might also be achieved through successful CR programmes. After the initiation of new pharmacological treatments, monitoring should take place throughout, also after $\mathrm{CR}$, and be clearly communicated when patients are discharged back to primary care. Additionally, education and lifestyle modifications can have an important impact on adherence to and maximising the effects of pharmacological treatment. CR has been shown to promote better medication adherence in patients after an acute coronary syndrome (ACS), and rates of adherence to pharmacological and lifestyle treatments are independently associated [50]. Therefore, integration of pharmacological residual risk management with CR and a seamless transition to long-term management by primary caregivers is essential to optimise long-term risk management.

\section{Transmural care pathways}

Transmural care pathways can be an important facilitator for better alignment of CR programmes with primary care risk management, enabling the transfer of prevention programme components out of the $\mathrm{CR}$ centre at an early stage when possible. On the other hand, they facilitate the extension of duration of treatment modules inside the CR centre when indicated (e.g. in cases of high disease complexity). As an example, in non-complex CR patients the exercise programme can take place in a primary care physical therapy practice near the patients' home environment. However, if parts of the CR programme are performed outside the CR centre, quality of care should be warranted by appropriate education of staff, monitoring of treatment results and benchmarking. In addition, the CR centre should still coordinate the multidisciplinary care of CR patients and, if necessary, primary caregivers should be given the opportu- 
nity to participate in multidisciplinary team meetings. Another requirement for the implementation of such transmural care programmes is reimbursement for exercise programmes in primary care, which should be nationally available. Finally, to ensure collaboration between primary caregivers and hospitals or CR centres, connected and synchronised ICT systems should be developed to suit both parties' needs. An example of a transmural care pathway is the Netherlands Society of Cardiology (NVVC) Connect programme with transmural agreements and collaboration for patients after an ACS, launched in 2011. Furthermore, Chronisch Zorgnet - a network of specialised primary care physical therapists for the delivery of primary care exercise programmes in the Netherlands-is currently being formed. Collaborating with such a network as part of the national NVVC Connect programme may help to increase the quality of care delivered by both primary and secondary caregivers.

\section{Conclusion and future directions}

CR has evolved as an important part of the treatment of CVD. However, to date, its full potential is fairly underutilised. Improving adherence to CR, especially in underrepresented patient groups, and providing CR for new target groups that would likely benefit from CR, could further reduce morbidity and mortality. Furthermore, telerehabilitation and loyalty programmes are promising new CR delivery modes to increase participation and to optimise the long-term effects of CR. Finally, CR and secondary prevention programmes may be improved substantially by the integration of $\mathrm{CR}$ in residual risk management and transmural care pathways. To benefit fully from the potential of CR, we should seize the opportunities to reshape current CR programmes, broaden their applicability and incorporate them into or combine them with other cardiovascular care programmes.

Conflict of interest T. Vromen, R.W.M. Brouwers, H.T. Jorstad, R.A. Kraaijenhagen, R.F. Spee, M.E. Wittekoek, M.J. Cramer, J.M.C. van Hal, L. Hofstra, P.M.J.C. Kuijpers, E.C. de Melker, S.F. Rodrigo, M. Sunamura, N.H.M.K. Uszko-Lencer and H.M. Kemps declare that they have no competing interests.

Open Access This article is licensed under a Creative Commons Attribution 4.0 International License, which permits use, sharing, adaptation, distribution and reproduction in any medium or format, as long as you give appropriate credit to the original author(s) and the source, provide a link to the Creative Commons licence, and indicate if changes were made. The images or other third party material in this article are included in the article's Creative Commons licence, unless indicated otherwise in a credit line to the material. If material is not included in the article's Creative Commons licence and your intended use is not permitted by statutory regulation or exceeds the permitted use, you will need to obtain permission directly from the copyright holder. To view a copy of this licence, visit http://creativecommons.org/licenses/by/4.0/.

\section{References}

1. West RR, Jones DA, Henderson AH. Rehabilitation after myocardial infarction trial (RAMIT): multi-centre randomised controlled trial of comprehensive cardiac rehabilitation in patients following acute myocardial infarction. Heart. 2012;98:637-44.

2. de Vries H, Kemps HM, van Engen-Verheul MM, et al. Cardiac rehabilitation and survival in a large representative community cohort of Dutch patients. Eur Heart J. 2015;36:1519-28.

3. Eijsvogels T, Maessen MFH, Bakker EA, et al. Association of cardiac rehabilitation with all-cause mortality among patients with cardiovascular disease in the Netherlands. JAMANetw Open. 2020;3:e2011686-1.

4. Goel K, Lennon RJ, Tilbury RT, et al. Impact of cardiac rehabilitation on mortality and cardiovascular events after percutaneous coronary intervention in the community. Circulation. 2011;123:2344-52.

5. Rauch B, Davos DH, Doherty P, etal. The prognostic effect of cardiac rehabilitation in the era of acute revascularisation and statin therapy: a systematic review and meta-analysis of randomized and non-randomized studies-The Cardiac Rehabilitation Outcome Study (CROS). Eur J Prev Cardiol. 2016;23:1914-39.

6. Anderson L, Thompson DR, Oldridge N, et al. Exercisebased cardiac rehabilitation for coronary heart disease. Cochrane Database Syst Rev. 2016;5:CD001800.

7. Knuuti J, Wijns W, Saraste A, et al. 2019 ESC Guidelines for the diagnosis and management of chronic coronary syndromes. Eur Heart J.2020;41:407-77.

8. Alswyan AH, Sauer Liberato AC, Dougherty CM. A systematic review of exercise training in patients with cardiac implantable devices. J Cardiopulm Rehabil Prev. 2018;38:70-84.

9. Smart NA, King N, Lambert JD, et al. Exercise-based cardiac rehabilitation improves exercise capacity and healthrelated quality of life in people with atrial fibrillation: a systematic review and meta-analysis of randomised and nonrandomised trials. Open Hear. 2018;5:e880.

10. van Engen-Verheul M, de Vries H, Kemps H, et al. Cardiac rehabilitation uptake and its determinants in the Netherlands. Eur J Prev Cardiol. 2013;20:349-56.

11. Kotseva K, Wood D, De Bacquer D. Determinants of participation and risk factor control according to attendance in cardiac rehabilitation programmes in coronary patients in Europe: EUROASPIRE IV survey. Eur J Prev Cardiol. 2018;25:1242-51.

12. Clark AM, King-Shier KM, Duncan A, et al. Factors influencing referral to cardiac rehabilitation and secondary prevention programs: a systematic review. Eur J Prev Cardiol. 2013;20:692-700.

13. De Vos C, Li X, Van Vlaenderen I, et al. Participating or not in a cardiac rehabilitation programme: factors influencing a patient's decision. Eur J Prev Cardiol. 2013;20:341-8.

14. Kotseva K, Wood D, De Bacquer D, et al. EUROASPIRE IV: a European Society of Cardiology survey on the lifestyle, risk factor and therapeutic management of coronary patients from 24 European countries. Eur J Prev Cardiol. 2016;23:636-48.

15. Revalidatiecommissie NVVC / NHS en projectgroep PAAHR. Multidisciplinaire Richtlijn Hartrevalidatie 2011. Utrecht: Nederlandse Vereniging Voor Cardiologie; 2011.

16. Pathak RK, Middeldorp ME, Lau DH, et al. Aggressive risk factor reduction study for atrialfibrillation andimplications for the outcome of ablation. The ARREST-AF cohort study. JAm Coll Cardiol. 2014;64:2222-31. 
17. Pathak RK, Middeldorp ME, Meredith M, et al. Longterm effect of goal-directed weight management in an atrial fibrillation cohort. A long-term follow-up study (LEGACY). JAm Coll Cardiol. 2015;65:2159-69.

18. Risom SS, Zwisler AD, Johansen PP, et al. Exercise-based cardiac rehabilitation for adults with atrial fibrillation. Cochrane Database Syst Rev. 2017; https://doi.org/10. 1002/14651858.CD011197.pub2.

19. Kirchhof P, Benussi S, Kotecha D, et al. 2016 ESC Guidelines for the management of atrial fibrillation developed in collaboration with EACTS. Eur HeartJ. 2016;37:2893-962.

20. Ponikowski P, Voors AA, Anker SD, et al. 2016 ESC guidelines for the diagnosis and treatment of acute and chronic heart failure: the Task Force for the diagnosis and treatment of acute and chronic heart failure of the European Society of Cardiology (ESC) developed with the special contribution of the Heart Failure Association (HFA) of the ESC. Eur Heart J.2016;37:2129-200.

21. Achttien RJ, Vromen T, Staal JB, et al. Development of evidence-based clinical algorithms for prescription of exercise-based cardiac rehabilitation. Neth Heart J. 2015;23:563-75.

22. Maron DJ, Hochman JS, Reynolds HR, et al. Initial invasive or conservative strategy for stable coronary disease. N Engl JMed. 2020;382:1395-407.

23. Hambrecht R, Walther C, Möbius-Winkler S, et al. Percutaneous coronary angioplasty compared with exercise training in patients with stable coronary artery disease: a randomized trial. Circulation. 2004;109:1371-8.

24. Mobius-Winkler S, Uhlemann M, Adams V, et al. Coronary collateral growth induced by physical exercise results of the impact of intensive exercise training on coronary collateral circulation in patients with stable coronary artery disease (EXCITE) trial. Circulation. 2016;133:1438-48.

25. van den Houten MM, Lauret GJ, Fakhry F, et al. Costeffectiveness of supervised exercise therapy compared with endovascular revascularization for intermittent claudication. BrJ Surg. 2016;103:1616-25.

26. Szot W, Zajac J, et al. The effect of cardiac rehabilitation and overall physical capacity and myocardial perfusion in women with microvascular angina. Kardiol Pol. 2016;74:431-8.

27. Kissel CK, Nikoletou D. Cardiac rehabilitation and exercise prescription in symptomatic patients with non-obstructive coronary artery disease-a systematic review. Curr Treat Options Cardiovasc Med. 2018;20:78.

28. SunamuraM, TerHoeveN, Geleijnse ML, etal. Cardiacrehabilitationin patientswhounderwent primarypercutaneous coronary intervention for acute myocardial infarction: determinants of programme participation and completion. Neth Heart J. 2017;25:618-28.

29. Suaya JA, Stason WB, Ades PA, et al. Cardiac rehabilitation and survival in older coronary patients. J Am Coll Cardiol. 2009;54:25-33.

30. Prescott E, Eser P, Mikkelsen N, et al. Cardiac rehabilitation of elderly patients in eight rehabilitation units in western Europe: outcome data from the EU-CaRE multi-centre observational study. Eur J Prev Cardiol. 2020;27:1716-29.

31. Vigorito C, Abreu A, Ambrosetti M, et al. Frailty and cardiac rehabilitation: a call to action from the EAPC Cardiac Rehabilitation Section. Eur J Prev Cardiol. 2017;24:577-90.

32. Colbert JD, Martin BJ, Haykowsky MJ, et al. Cardiac rehabilitation referral, attendance and mortality in women. EurJPrev Cardiol. 2015;22:979-86.

33. De Smedt D, de Bacquer D, de Sutter J, et al. The gender gap in risk factor control: effects of age and education on the control of cardiovascular risk factors in male and female coronary patients. The EUROASPIRE IV study by the European Society of Cardiology. Int J Cardiol. 2016;209:284-90.

34. Witvrouwen I, van Craenenbroeck EM, Abreu A, et al. Exercise training in women with cardiovascular disease: differential response and barriers-review and perspective. Eur J Prev Cardiol. 2019; https://doi.org/10.1177/ 2047487319838221.

35. Audelin MC, Savage PD, Ades PA. Changing clinical profile of patients entering cardiac rehabilitation/secondary prevention programs: 1996 to 2006. J Cardiopulm Rehabil Prev. 2008;28:299-306.

36. Ades PA, Savage PD, Toth MJ, et al. High-calorie-expenditure exercise: a new approach to cardiac rehabilitation for overweight coronary patients. Circulation. 2009;119:2671-8.

37. Minneboo M, Lachman S, Snaterse M, et al. Community-based lifestyle intervention in patients with coronary artery disease: the RESPONSE-2 trial. J Am Coll Cardiol. 2017;70:318-27.

38. Clark RA, Conway A, Poulsen V, Keech W, Tirimacco R, Tideman P. Alternative models of cardiac rehabilitation: a systematic review. Eur J Prev Cardiol. 2015;22:35-74.

39. Frederix I, Vanhees L, Dendale P, et al. A review of telerehabilitation for cardiac patients. J Telemed Telecare. 2015;21:45-53.

40. Huang K, Liu W, He D, et al. Telehealth interventions versus center-based cardiac rehabilitation of coronary artery disease: a systematic review and meta-analysis. Eur J Prev Cardiol. 2015;22:959-71.

41. Frederix I, Caiani EG, Dendale P, et al. ESC e-Cardiology Working Group Position Paper: overcoming challenges in digital health implementation in cardiovascular medicine. EurJ Prev Cardiol. 2019;26:1166-77.

42. Brouwers RWM, van Exel HJ, van Hal JMC. et al. Cardiac telerehabilitation as an alternative to centre-based cardiac rehabilitation. Neth Heart J.2020;28:443-451.

43. Marteau TM, Hollands GJ, Fletcher PC. Changing human behavior to prevent disease: the importance of targeting automatic processes. Science. 2012;337:1492-5.

44. MantzariE, VogtF, ShemiltI, WeiY,HigginsJPT, MarteauTM. Personal financial incentives for changing habitual healthrelated behaviors: a systematic review and meta-analysis. PrevMed. 2015;75:75-85.

45. Keesman M, Janssen V, Kemps H, et al. BENEFIT for all: an ecosystem to facilitate sustained healthy living and reduce the burden of cardiovascular disease. Eur J Prev Cardiol. 2019;26:606-8.

46. JorstadHT, von Birgelen C, Alings MW, etal. Effect of a nursecoordinated prevention programme on cardiovascular risk after an acute coronary syndrome: main results of the RESPONSE randomised trial. Heart. 2013;99:1421-30.

47. Hermans MP, Fruchart JC. Reducing residual vascular risk in patients with atherogenic dyslipidemia: where do we go from here? Clin Lipidol. 2010;5:811-26.

48. Bhatt DL, Steg PG, Miller M, et al. Cardiovascular risk reduction with icosapent ethyl for hypertriglyceridemia. NEngl J Med. 2019;380:11-22.

49. Bohula EA, Wiviott SD, McGuire DK, et al. Cardiovascular safety of lorcaserin in overweight or obese patients. NEngl J Med. 2018;379:1107-17.

50. Griffo R, Ambrosetti M, Tramarin R, et al. Effective secondary prevention through cardiac rehabilitation after coronary revascularization and predictors of poor adherence to lifestyle modification and medication. Results of the ICAROS survey. Int J Cardiol. 2013;167:1390-5. 